\section{UKCPR}

University of Kentucky

Center for

Poverty Research

\section{Discussion Paper Series}

DP 2007-02

ISSN: 1936-9379

\title{
Transitions into and out of the WIC program: A cause for concern?
}

\author{
Alison Jacknowitz \\ Department of Public Administration and Policy \\ American University \\ jacknowi@american.edu \\ Laura Tiehen \\ Economic Research Service \\ ltiehen@ers.usda.gov
}

July 2007

\section{Preferred citation}

Jacknowitz, A., and Tiehen, L. (2007, July). Transitions into and out of the WIC program: A cause for concern? University of Kentucky Center for Poverty Research Discussion Paper Series, DP2007-02. Retrieved [Date] from http://www.ukcpr.org/Publications/DP2007-02/pdf.

This project was supported with a grant from the UK Center for Poverty Research through the U.S. Department of Health and Human Services, Office of the Assistant Secretary for Planning and Evaluation, grant number 2U01PE000002-04. The opinions and conclusions expressed herein are solely those of the author(s) and should not be construed as representing the opinions or policy of the UKCPR or any agency of the Federal government. 
Transitions Into and Out of the WIC Program: A Cause for Concern?

Despite the health benefits of participation in the Special Supplemental Nutrition Program for Women, Infants, and Children (WIC), many eligible households do not participate in WIC during pregnancy and others exit WIC after a child turns one year old. This research uses the first two waves of the Early Childhood Longitudinal Study-Birth Cohort (ECLS-B) to advance our understanding of these transitions into and out of WIC. Findings suggest that those who exhibit better economic health across a variety of dimensions are more likely to delay entry into the program or exit after a child turns one year of age. 


\section{Introduction}

The Special Supplemental Nutrition Program for Women, Infants, and Children (WIC) provides nutritious foods, nutrition counseling, and referrals to health and other social services to low-income pregnant and postpartum women and their infants and children up to age five. WIC has grown from serving 88,000 participants in fiscal year 1974 to approximately 8.1 million in fiscal year 2006 [US Department of Agriculture (USDA), 2007]. In fiscal year 2006, approximately one quarter of participants were pregnant or postpartum women, approximately one quarter were infants, and approximately half were children between one and five years of age (USDA, 2007).

While participation in the WIC program has increased since the program's inception, not all individuals who are eligible for WIC participate and participation rates vary by low-income target group. Among eligible individuals in 2003, participation rates are highest among postpartum women (74 percent for all postpartum women, 68.1 percent for breastfeeding women, and 78.8 percent for non-breastfeeding women) and infants (83.1 percent) (USDA, 2006). Pregnant women are less likely to participate than their postpartum counterparts with a participation rate of 69.6 percent (USDA, 2006). Finally, children ages one through five have the lowest participation rate (45.3 percent) (USDA, 2006). Hence, this study focuses on participants who delay entry until the postnatal period and those who exit when a child reaches age one.

While pregnant women and children have the lowest participation rates, research on the health benefits of WIC participation is strongest for these two groups. Research has focused on evaluating the effects of prenatal WIC participation and participation when a child is between one and five years of age (Currie, 2003; Fox, Hamilton, and Lin, 2004). Recent reviews of the literature by Currie (2003) and Fox, Hamilton, and Lin (2004) conclude that research, taken as a 
whole, suggests that WIC has a positive impact on several key prenatal and birth outcomes such as intake of food energy and nutrients during pregnancy, the likelihood of low birthweight, and mean birthweight and gestational age. ${ }^{1}$ The evidence on the benefits of WIC participation as a child is not as extensive or consistent as that for the prenatal period; however, the literature strongly suggests that the benefits of WIC include increased intake of vitamins and minerals such as iron, folate, and vitamin B6 (Currie, 2003; Fox, Hamilton, and Lin, 2004). In addition, some evidence indicates that WIC improves children's growth, health care use, immunization status, and overall health (Fox, Hamilton, and Lin, 2004).

Furthermore, studies demonstrate that eligible pregnant women and children who do not participate while pregnant or a child under the age of five still exhibit need across a variety of dimensions (Bitler, Gundersen, and Marquis, 2005; Gundersen, 2005; Tiehen and Jacknowitz, 2007). For example, Bitler, Gundersen, and Marquis (2005) find that among eligible children who did not participate in WIC, 5.5 percent live in households that are food insufficient and 19.5 percent live in households that could not afford to eat balanced meals. Focusing on pregnant women, Tiehen and Jacknowitz (2007) find that 32.7 percent of eligible non-participants are below the poverty line.

Eligible pregnant women and children who do not participate in the WIC program demonstrate need and can potentially benefit from program services. These groups are of particular importance given their relatively low participation rates and the research evidence that they accrue the greatest health benefits from participation. This paper uses the first two waves of the Early Childhood Longitudinal Study-Birth Cohort (ECLS-B) data set to advance our understanding of factors explaining why eligible participant households are less likely to

\footnotetext{
${ }^{1}$ While the evidence taken as a whole suggests that WIC has positive effects in the prenatal period, there is a current debate in the literature concerning the program's effectiveness. See Bitler and Currie (2005), Joyce, Gibson, and Colman (2005), and Ludwig and Miller (2005) for more information on this debate.
} 
participate in the prenatal period and after a child turns one year of age than in the year after birth. Specifically, we examine factors associated with WIC participants' decisions to 1) delay their entry into the WIC program until the postnatal period and 2) exit the program early after the child turns one year of age. In addition to identifying demographic, socio-economic, state economic conditions, and WIC state policies associated with these two transitions into and out of the WIC program, we also examine self-reported information from households on their reasons for exiting the program after their child turns one year of age.

From a program perspective, if those who are not participating in all periods are more advantaged economically and do not appear to need program benefits, then the program is welltargeted. If eligible non-participants do exhibit need, results can be used to facilitate outreach efforts and to guide program reforms to increase the length of participation among these households. Given that households that participate at some point demonstrate the willingness to participate and program awareness (at least for those exiting after the child turns one year of age), outreach activities and program re-design efforts should be most effective among this group.

\section{The WIC Program}

\subsection{Services}

The overarching objective of the WIC program is to counteract the negative effects of poverty on prenatal and child health. WIC provides food and services to the following five lowincome target groups: pregnant women, non-breastfeeding postpartum women up to six months, breastfeeding postpartum women up to one year, infants, and children up to their fifth birthday. WIC participants typically receive vouchers to purchase specific supplemental foods from 
authorized retailers. These foods are good sources of nutrients such as protein, iron, calcium, and vitamins A and C.

WIC food packages do not vary by household income; however, they vary by lowincome target group and state of residence. WIC food packages for most participant categories other than infants include milk, eggs, cheese, dried beans, peanut butter, and breakfast cereals that are high in iron and low in sugar. Infants who are not exclusively breastfed receive ironfortified infant formula from zero to twelve months of age as well as infant cereal and fruit or vegetable juice from four to twelve months of age. The price of infant formula is a large source of variation in the value of food packages across participant categories. In 2002, the average retail value of the food package for infants four to twelve months of age was $\$ 100.37$ per month while the average retail value of the child package was $\$ 39.29$ per month (Institute of Medicine, 2005). In addition, while federal guidelines limit the maximum amount of food in each food package, states have some discretion over the content of food packages. For example, some states allow WIC agencies to tailor the sucrose content or the type of milk in the food packages of some participants.

In addition to the supplemental foods, WIC also provides nutrition education to its participants. Nutrition education includes lessons on recommended food patterns, but can also include information on breastfeeding and health behaviors such as avoiding alcohol, smoking, and drugs. States must offer participants two nutritional education sessions every six months, but participants are not required to attend them. The final component of WIC services is referral to health and social services such as preventative medicine and other assistance programs particularly Medicaid.

\subsection{Eligibility}


In addition to being categorically eligible (i.e., belonging to one of the five groups discussed earlier), an individual must meet two other criteria to be eligible to receive WIC. First, the household must reside in a household with income at or below 185 percent of the federal poverty threshold (i.e., income eligible) or be enrolled in another assistance program such as the Food Stamp Program, Temporary Assistance for Needy Families (TANF), or Medicaid (i.e., adjunctively eligible). Some states allow participants in the National School Lunch Program or the Supplemental Security Income (SSI) Program to be adjunctively eligible for WIC. Second, the individual must be assessed as nutritionally at risk. Two types of nutritional risk are recognized for WIC eligibility: (1) medically-based risks such as anemia, underweight, overweight, or history of pregnancy complications or poor outcomes; and (2) diet-based risks such as failure to meet dietary guidelines. Again, states vary on how they collect information about nutritional risk. For example, some states require individuals to recall food intake over a 24-hour period and others just require that individuals complete a food frequency checklist.

Participants are certified as eligible for a specified period of time, which varies by participant category. A pregnant participant is certified for the duration of her pregnancy and does not have to recertify her eligibility until six weeks after the birth of her infant. Postpartum women who do not breastfeed are eligible for WIC for up to six months after delivery, while mothers who breastfeed are certified for six months at a time up to one year after delivery as long as they continue to breastfeed. Infants are generally certified until age one, while children age one to five are certified for a six-month period. For additional information on WIC eligibility, see the US Department of Agriculture Food and Nutrition Service website at http://www.fns.usda.gov/wic/howtoapply/eligibilityrequirements.htm.

\subsection{Literature}


The majority of national-level studies of WIC participation have examined factors associated with WIC participation using a cross-sectional design [Bitler and Currie (2005), Bitler, Currie, and Scholz (2003), Brien and Swann (2001), Chatterji et al. (2002), Hernandez and Ziol-Guest (2006), Kowaleski-Jones and Duncan (2000), and Ku, (1989)], while others have used a more dynamic design (Burstein et al., 2000; Gundersen, 2005; Swann, 2007; Tiehen and Jacknowitz, 2007). Most of these studies focus on prenatal participation, while three focus on children’s participation (Burstein et al., 2000; Gundersen, 2005; Hernandez and Ziol-Guest, 2006). Two other studies examine the correlates of WIC participation around the birth of a child, though they do not distinguish prenatal from postnatal participation (Bitler, Currie, and Scholz, 2003; Chatterji et al., 2002). ${ }^{2}$

Among the studies that focus on prenatal participation, some have the primary objective of understanding factors that influence prenatal participation [(Ku (1989), Swann (2007), and Tiehen and Jacknowitz (2007)] while others focus on understanding prenatal participation as part of an effort to estimate the effect of WIC on birth outcomes (Bitler and Currie, 2005; Brien and Swann, 2001; Kowaleski-Jones and Duncan, 2000). ${ }^{3}$ The primary interest of Ku (1989), Swann (2007), and Tiehen and Jacknowitz (2007) is to understand factors associated with the timing of prenatal participation.

This study primarily builds upon work by Burstein et al. (2000) and Gundersen (2005). Gundersen (2005) uses the 1996 Survey of Income and Program Participation (SIPP) to compare the economic health of the following three groups of eligible infants and children: nonparticipants, participants who exit the program, and participants who remain in the program.

\footnotetext{
${ }^{2}$ Chatterji et al. (2002) examine WIC participation during the year of a child's birth (i.e., end of pregnancy and immediately after birth) as part of a study that examines the effect of WIC on breastfeeding.

${ }^{3}$ These studies employ other techniques to address the possible selection bias in estimating the effect of WIC on birth outcomes. However, the results of their estimation of prenatal WIC participation are of primary interest to this study.
} 
Gundersen (2005) finds that across all of the measures of economic health examined those infants who never participate are better off than those infants who do participate. In addition, participants who exit the program are better off than those who remain in the program, except that they are more likely to have family income below 50 percent of the poverty line. Burstein et al. (2000) produce similar results to those found by Gundersen (2005). They examine factors associated with exits from the WIC program as a child using the 1992 and 1993 panels of the SIPP and find that exits are most strongly associated with an increase in earnings by a household member, an addition of a household member with earnings, an exit from cash assistance, and a geographical move (Burstein et al., 2000).

This paper contributes to the literature on several fronts. First, we examine the dynamics of WIC participation from a woman's pregnancy until her child reaches age one. No previous study has examined the dynamics of WIC participation over this time frame; Swann (2007) and Tiehen and Jacknowitz (2007) focus on pregnant women participants and Burstein et al. (2000) and Gundersen (2005) study infant and/or child participants. Next, we examine why women who receive WIC participate in the postnatal period do not enter the program earlier, which to our knowledge has not been examined. Third, in addition to examining characteristics associated with the decision for infants to leave as children we also examine mothers' reasons for these exits. Such information has not been available in a nationally-representative survey. Next, by focusing on households who participated in the program, we reduce the role of stigma as a possible explanation for periods of non-participation. In addition, we eliminate lack of program awareness as an explanation for infants exiting after turning one year of age since they participated previously in WIC. Sixth, we use a current, nationally-representative data set that captures the time period after recent policy changes which have standardized WIC eligibility 
requirements and recent expansions of Medicaid eligibility. Finally, the data also contain rich covariates such as breastfeeding status and allow us to distinguish between WIC participation periods reasonably well.

\section{Data}

\subsection{ECLS-B}

The primary data source for this study is the Early Childhood Longitudinal Study-Birth Cohort. The ECLS-B is a longitudinal data set collected by the National Center for Education Statistics (NCES). The baseline sample of 10,700 out of approximately 14,000 selected children was designed to be nationally-representative of children born in 2001 with over samples of children who are American Indian, Chinese, a member of another Asian and Pacific Islander group, a twin, and low and very low birthweight children. ${ }^{4}$ The ECLS-B follows these children from birth through kindergarten with data collection occurring when the child is nine months of age, two years of age, approximately four years of age (at pre-school), and at kindergarten entry. To date, the first two waves (nine-month and two-year data collection) of survey data are available and used in this study. Of the 10,700 children with a parent who participated in the first wave of the survey, 9,850 of their parents participated in the second wave. Non-response rates for the second wave of the survey are fairly similar across maternal education, region of residence, and child's race ethnicity (Nord et al., 2006). For additional information on the ECLSB, see survey instruments available from NCES. ${ }^{5}$

Given that the broad motivations of the ECLS-B include understanding children's health care and status, growth and development, transitions to child care and early childhood education

\footnotetext{
${ }^{4}$ All unweighted sample sizes are rounded to the nearest 50 per NCES rules governing use of restricted data.

${ }^{5}$ Survey instruments are available from NCES at http://nces.ed.gov/ecls/Birth.asp.
} 
programs, and school readiness, these data are quite rich. In the first two waves of the data, information is collected from children and both parents, including non-residential fathers, birth certificates, and child care providers. Pertinent to this paper, the ECLS-B contains information on the timing of WIC participation, explanations for exiting the WIC program, demographic characteristics, income and assets, participation in other assistance programs, and health status and behaviors. The ECLS-B is the most appropriate available data source for this study, even relative to the SIPP, because it follows a large sample of children from the birth, contains rich covariates such as breastfeeding status, and provides self-reported information from program leavers on why they left WIC.

\subsection{Additional Data Sources}

Because some WIC policies vary at the state-level, we use data on 2000 state policies from the WIC Participants and Program Characteristics 2000. State policies of interest include the benefits of WIC food packages (e.g., the value of the food package) and the transactions costs of enrolling in WIC and receiving the food packages (e.g., whether WIC vouchers are issued monthly or less frequently). For more information on these state policies see Appendix A.

The second additional source of 2000 data is Maternal and Child Health (MCH) Update: States Have Expanded Eligibility and Increased Access to Health Care for Pregnant Women and Children. Medicaid participants are deemed adjunctively-eligible for WIC, and the income threshold for Medicaid varies by state and can be higher than the income threshold for WIC eligibility. Therefore, we use state Medicaid income eligibility thresholds for pregnant women to determine eligibility for the program.

Finally, data on the 2000 state unemployment rates are from the US Bureau of Labor Statistics and the 2000 state poverty rates are from the US Census Bureau. 
We use 2000 data, the most recent information available on WIC state policies, which we believe is appropriate for use in this study. While all of the children in the sample were born during 2001, many of their mothers were pregnant during 2000. Women pregnant in 2000 would face the 2000 policies and would make WIC participation decisions based on them in 2001. It is unlikely that WIC state policies changed over the period of our study as Bitler and Currie (2005) and USDA (2002) note that these policies changed little over the 1990s. Therefore, households that were deciding in 2001 or 2002 whether to enter WIC in the postnatal period or exit WIC in the child period most likely faced the same policies that were in place in 2000. For consistency, we use 2000 Medicaid state policies and state economic conditions as well.

\subsection{Coding WIC Eligibility and Participation}

To be eligible to receive WIC services an individual must meet categorical, income, and nutritional risk requirements. To meet the income requirement, a household must have income at or below 185 percent of the poverty line or participate in the Food Stamp Program, TANF, or Medicaid. If the state's income threshold for Medicaid is higher than 185 percent of the income to poverty ratio we use that threshold to determine eligibility. To determine whether a household's income is less than or equal to 185 percent of the poverty line, the household income to poverty ratio is calculated using household income over the past year from the nine-

month survey, household size from the nine-month survey, and US Department of Health and Human Services poverty guidelines. Because the income information is bracketed, the midpoint of each bracket is used to calculate the income to poverty ratio. All households who report using Medicaid to pay for prenatal care are considered adjunctively eligible for the WIC program.

There are some notable limitations to using the ECLS-B for coding WIC eligibility that may cause us to misclassify households. First, as described above, we define our sample of 
eligible households based on information from the nine-month survey. The ECLS-B does not provide adequate information to allow us to precisely model changes in eligibility over the three time periods of our study. Therefore, we focus on a fixed sample of households in which the mother was eligible in the prenatal period. We discuss how changes in eligibility status may affect our results later in the paper. Next, using the midpoint of the income brackets means that a household whose income falls within an income bracket that contains the relevant eligibility threshold may be assigned the wrong eligibility status. However, Tiehen and Jacknowitz (2007) test other methods of coding income to determine eligibility and their results are not sensitive to these different specifications.

Third, respondents' report their household income for the year prior to the survey. Therefore, the income variable is capturing income during the prenatal and postnatal period. Because mothers might take leave from work after giving birth we may underestimate their income in the prenatal period and hence, code ineligible households as eligible. A second issue related to the use of annual household income to determine eligibility is that many WIC agencies use monthly income to determine eligibility. While WIC agencies have wide discretion over the time period used to determine a household's income, Bitler, Currie, and Scholz (2003) suggest that most agencies use monthly income to calculate eligibility. Ver Ploeg and Betson (2003) note that, given WIC certification periods, the use of annual income to determine eligibility will underestimate the number of eligible households, because households with annual income above 185 percent of the poverty guideline but at least one month of income eligibility will be misclassified as ineligible. We find that 250 households in the sample reported prenatal WIC participation, but are coded as ineligible. ${ }^{6}$

\footnotetext{
${ }^{6}$ There are other explanations for the presence of 250 ineligible WIC participants in the ECLS-B, such as misreporting of income to the WIC agency, or misreporting of income or WIC participation in the ECLS-B.
} 
Fourth, the ECLS-B does not include data to determine whether a woman is at nutritional risk. However, this should not affect results from the study as nearly all income-eligible individuals are also at nutritional risk (Ver Ploeg and Betson, 2003). Finally, the ECLS-B does not have information on prenatal participation in the Food Stamp Program or TANF. This will lead us to misclassify as ineligible households who have annual income above 185 percent of the poverty line, but who participated in either the Food Stamp Program or TANF in the prenatal period. Given the stricter eligibility criteria for these two programs, this type of misclassification is likely to be minimal.

WIC participation is determined based on a series of questions asked about WIC participation in both waves of the survey. We code WIC participation at the household level as it is difficult to accurately identify postnatal maternal participation, infant participation, and different children's participation in the same household. In addition, our measures of participation capture any participation and not the duration of participation in a given time period. A household is coded as a prenatal participant if the mother indicates that she participated in WIC prior to giving birth. A household is considered to participate in the postnatal or infant period (hereafter referred to as the postnatal/infant period) if the mother responded that the mother used WIC vouchers to buy food for herself during the six months after giving birth, or if the mother used WIC vouchers to buy food for herself, the survey child, or twin during the 30 days before the nine-month survey and the child or twin was less than 12 months old at the time of the survey. Due to the time frame and wording of the WIC questions, it is difficult to fully capture the WIC participation of each individual in the household during the postnatal/infant period. Hence, analyzing WIC participation at the household-level will give us a more accurate picture of a household's use of services during this period. Finally, a household is considered a 
participant in the program in the child period if the mother responded that the child over 12 months old received WIC benefits in the last 30 days.

To gauge the accuracy of our measures of eligibility and participation, we compare WIC participation rates among all eligible households with those generated by USDA (2006). Overall, participation rates generated using the ECLS-B data are similar to those calculated by USDA for 2001 (2006). We calculate a participation rate of 68.5 percent among eligible prenatal households compared to that of 64 percent (USDA, 2006), which is produced using the methodology adopted by USDA on the recommendation of the National Research Council (Ver Ploeg and Betson, 2003). We do not estimate participation rates for the other groups as we do not model changes in eligibility. Further, Tiehen and Jacknowitz (2007) demonstrate that the demographic characteristics of prenatal WIC participants in the ECLS-B are quite similar to those generated using administrative data.

\subsection{Analysis Sample}

We construct an analysis sample of 4,050 eligible households who participated in WIC either during the prenatal period, the postnatal/infant period, or as a child. Households must meet the following seven criteria to be included in the analysis sample with the number of observations excluded for each criterion in parentheses. First, only observations with state identifiers are included (100). Second, only households with parents who participated in the second wave of data collection are included (850). Third, only households which contain the biological mothers of the survey child are included (150). Fourth, only one record per household is included, even if the woman has a multiple birth (750). Fifth, only households with a survey child 18 months of age or less in the first wave of data are included (50). We exclude mothers of infants over 18 months of age at the nine-month data collection because we cannot ascertain their 
prenatal WIC participation status due to the structure of the survey. Sixth, only households that are determined to be eligible in the prenatal period, have information on participation in all periods, and participated in WIC in any one of the periods are included $(4,650) .^{7}$ Finally, only observations with complete information for all relevant variables are included with the exception of the following three variables: first born, maternal welfare use as a child, and prematurity of the infant (100). ${ }^{8}$ Each of these variables has 40 or more missing values; therefore we assign the mode to each missing value data point, and include a variable that indicates whether the observation is missing data on that variable.

Tables 1a and 1b provide information on the transitions into and out of WIC participation between the prenatal period and the postnatal/infant period and the postnatal/infant period and child periods, respectively. For an illustration of all of the possible transitions into and out of the WIC program over the three time periods of our study, see Appendix B. Table 1a shows that the most significant transition between the prenatal and postnatal/infant periods is from nonparticipation in the prenatal period to participation in the postnatal period (delayed entry). Delayed entrants represent 16.6 percent of the analysis sample and 17.8 percent of postnatal/infant period participants. Note that very few (4.1 percent) households who participate in the prenatal period exit the program. Between the postnatal/infant and child periods, the most significant transition is by households that exit WIC when the child reaches age one (leavers). Leavers constitute 21.1 percent of the analysis sample and 22.6 percent of households that participate in the postnatal/infant period. We observe very few households entering WIC when

\footnotetext{
${ }^{7}$ Households who participated in WIC in the prenatal period, but are coded as ineligible, are excluded from the analysis sample (250). Because these ineligible participants are significantly more advantaged, on average, than eligible households and we cannot determine why they are misclassified, we exclude them from the analysis.

${ }^{8}$ The observations excluded for missing data have very similar socio-economic characteristics to those included in the analysis sample. Differences exist across the following variables: Hispanic, high school graduate, less than 20 years of age, US citizen, and mother employed during year before birth.
} 
the child is over age one (5.0 percent of the analysis sample). ${ }^{9}$ Given that the largest transitions occur with households delaying entry into the program until the postnatal period and exiting the program early as children, this paper focuses on understanding the factors that explain these two transitions.

\section{Empirical Strategy}

We use probit regression analysis to estimate equations explaining (1) delayed entry into the WIC program during the postnatal/infant period, and (2) early exit from the program when a child reaches age one. In the first equation the dependent variable is a binary variable with the value of 1 if the household entered the WIC program in the postnatal/infant period (delayed entrants, which correspond to groups 5 and 6 in Appendix B) and 0 if the household participated in both the prenatal and postnatal/infant periods (groups 1 and 2 in Appendix B). In the second equation, the dependent variable is a binary variable with the value of 1 if the household exited the program after the child turns the age of one (leavers, which correspond to groups 2 and 6 in Appendix B) and 0 if the household participated in both the postnatal/infant and the child periods (groups 1 and 5 in Appendix B). The unit of analysis is the household.

The equations include independent variables that may influence the transitions into and out of WIC through their influence on the size of the benefits, the transactions cost associated with participation, stigma, or the availability of information on the program as described by Currie (2006). ${ }^{10}$ Many of the included variables could be attributable to more than one of these explanations; therefore we do not assign each variable to a specific factor. We believe, by

\footnotetext{
${ }^{9}$ It is important to note that we only observe households up to the second wave of the survey, when the child is approximately two years old.

${ }^{10}$ Currie (2006) also mentions social networks and time preferences as factors that influence the decision to participate but we do not include variables to capture them as they are not available in the data.
} 
focusing on households who participated in the program, we reduce the role of stigma as a possible explanation for periods of non-participation. In addition, we eliminate lack of program awareness as an explanation for households exiting after the child turns one year of age since they participated previously in WIC. The equations also include independent variables to control for socio-economic characteristics. Some of these socio-economic characteristics such as the change in household income between the two survey waves and participation in the other assistance programs capture eligibility for the WIC program in later periods of our study. We estimate two versions of each regression equation. For the delayed entrant model, the first, more parsimonious, specification includes variables that capture factors occurring before the transition and those that are less likely to be considered choices made by households. For the leavers model, the more parsimonious specification excludes change in income status between the two waves. The second model for the delayed entrants and leavers, the full model, includes all variables, including choice variables, and is the same for the early exit and delayed entrants equations.

The characteristics displayed in table 2 are included as explanatory variables in at least one of the models. Unless noted all of the control variables are measured using data from the nine-month survey, which includes birth certificate data, to capture characteristics before participation decisions are made. The two-year data do not capture characteristics of participants until after the decision to exit the WIC program when a child turns one year of age. We include variables that indicate the mother's race and ethnicity (with Non-Hispanic white as the basis), the mother's education (with less than high school as the basis), the mother's age (with age less than 20 years as the basis), the mother's citizenship status from the second wave of data, the mother's marital status, the presence of child (other than the interview child or twin) under age 5 in the 
household, the presence of a child between the ages of 5 and 17 in the household, whether the mother has twins or a higher-order birth, and whether the interview child is the mother's first. We include indicator variables for the region of residence (with residence in the West as the basis), and for the population size of the locality the household lives in (with population of 50,000 and above as the basis).

We capture a women's experience with other assistance programs with an indicator variable for participation in either TANF, the Food Stamp Program, or Medicaid since the birth of the child. This variable is only included in the second specification of the delayed entry equation. We also include variables that capture her use of welfare as a child (with no cash welfare receipt as the basis).

We also include household income and an indicator variable for household income below the poverty line. In the full model, we include indicator variables for changes in household income between the nine-month and the two-year survey, (with household income remained the same as the basis). We characterize the woman's assets with indicator variables for home ownership, car or truck ownership, and for having investments. We include an indicator variable for being employed any time during the 12 months prior to the child's birth, and a variable to capture the mothers return to work after giving birth, which is excluded from the first model examining delayed entry into WIC.

To capture investments in health and health status we include variables to describe characteristics related to a woman's prenatal care and her infant's health. The equations include variables that indicate whether the woman had prenatal care other than her WIC visits and how she paid for it (with payment through private insurance as the basis). We include a variable that indicates that the woman has smoked at least 100 cigarettes during her lifetime, and a variable 
for the number weeks into her pregnancy when the mother found out she was pregnant, which we refer to as gestational age at pregnancy recognition.

A number of variables are included that are related to the infant's health and development. None of these variables are included in the first model examining delayed entry into WIC because many of them are choice variables. Two variables, which rely on information from both waves of data, capture the initiation and duration of breastfeeding. One variable indicates that the child was never breastfeed and the other variable indicates that the child was breastfed under six months (with the child breastfed six months or more as the basis). Two variables describe birth outcomes: an indicator for whether the child was low birthweight and an indicator for whether the child was born prematurely. An additional variable related to birth outcomes, the number of extra days the mother had to stay in the hospital due to a medical problem, is also included. The equation also includes three mutually-exclusive indicator variables for whether the child received well-baby care, whether the well-baby care visits were received at a clinic or health center, or whether the care was received at another place such as an emergency room (with well-baby care received at a doctor's office or health maintenance organization (HMO) as the basis).

We include two variables to describe the economic environment in the state-the poverty rate and the unemployment rate. In addition, variables are included to capture state-level WIC policies that may affect WIC participation. A number of these policies are expected to decrease the transactions cost of WIC participation. In some states, household receipt of Supplemental Security Income or Free or Reduced Price National School Lunch Program confers income eligibility for WIC, so that participants in these programs do not have to document income to establish income eligibility. The number of WIC offices per 1,000 poor people in the state is 
included as a measure of access to the program. WIC-only stores are designed to facilitate the redemption of WIC vouchers and reduce the stigma of doing so. Therefore, we also include the number of WIC-only stores per 1,000 poor people in the state.

Another set of state policy variables is expected to increase the transactions cost of WIC participation. One variable indicates whether states require prenatal WIC participants to pick up WIC vouchers every month, rather than every two or three months. A variable is included to indicate that the state documents every identified nutritional risk of participants, rather than just the primary nutritional risks. We include an indicator variable for whether WIC offices in the state collect dietary intake information from all, rather than just high-risk, participants and an indicator variable for whether dietary intake information is collected through 24-hour recall, which is estimated to be more time-consuming than a food frequency checklist, the other primary method for collecting dietary intake information (Institute of Medicine, 2002). We also include an interaction term that indicates that the state both collects dietary intake information from all participants and uses 24-hour recall as the data collection method.

Finally, three variables are included to represent state-level differences in the WIC benefit packages. Two of the variables indicate whether a certified WIC staff person is allowed by the state to tailor an individual's food package according to their nutritional needs or preferences. One variable indicates whether the state allows caseworkers to specify the type of milk to reduce fat, lactose, or calories and another variable indicates whether the state allows the sucrose content of cereal to be reduced. It is not clear how these tailoring practices will influence WIC participation. The average retail value of the WIC food package, which can vary across states as a result of food package tailoring practices and differences in food prices, is also included. 
All probit regressions are weighted using the weight variable, W2RO, which is provided with the ECLS-B. Marginal effects evaluated at the means of the independent variables are presented, and standard errors are adjusted to account for heteroskedasticity and for clustering at the state level since all mothers in a state face the same WIC policies and environment.

\section{Results}

\subsection{Postnatal/Infant WIC Entrants}

As shown in table 2, delayed entrants appear to be more advantaged than households that participate in both the prenatal and postnatal/infant periods along a variety of dimensions including maternal education, maternal age, marital status, participation in other assistance programs, assets, employment, and utilization of private insurance to pay for Medicaid. The results of the probit regression of postnatal WIC entry are displayed in table 3. The estimated marginal effects from a probit regression with our parsimonious specification are displayed in column (1) and from our full specification including choice variables and variables measured after birth are in column (2). Because the results between these two models are similar, we focus on the full model in column (2).

These regression results provide some evidence that WIC participants in better economic circumstances are more likely to delay WIC participation until the postnatal/infant period. WIC participants with higher maternal education, higher household income, and with the mother employed the year before birth are more likely to delay entrance until the postnatal/infant period. These factors suggest that households that delay entry into the program may not have been eligible in the prenatal period. It is also possible that mothers who worked the year before birth were eligible but did not have the time to enroll during the prenatal period. Households where 
the mother is a US citizen are less likely to delay entry until the postnatal/infant period. Unlike many other social assistance programs, WIC extends eligibility to non-citizens. However, it appears that many non-citizen WIC participants do not take advantage of WIC until after having a child. Interestingly, the infant would be considered a US citizen; suggesting the mother may not be aware that she is eligible during the prenatal period.

The regression results also indicate a strong relationship between prenatal Medicaid coverage and prenatal receipt of WIC. Compared to those with private health insurance, WIC participants who have Medicaid coverage during the prenatal period are 11.7 percentage points less likely to delay WIC participation until the postnatal period. Given that participation in Medicaid provides adjunctive eligibility for WIC this is not surprising. Those with neither private insurance nor Medicaid are also less likely to delay receipt of WIC until the postnatal period, although the estimated marginal effect is much smaller.

We find a positive association between postnatal WIC entrance and health-related problems after the infant's birth . Spending extra days in the hospital is associated with a greater likelihood of postnatal entrance into the WIC program, although the estimated marginal effect is quite small. Further having a low birthweight child is associated with a delay in entry. These results suggest that these health problems during childbirth may motivate households to invest in WIC or may increase their exposure to health professionals who provide them with information about the WIC program. The result that those who received no prenatal care are more likely to delay entry into WIC is consistent with both of these explanations for postnatal entrance into WIC.

There is also evidence that geographic location may be a factor in the timing of WIC participation; women who reside in the Northeast region and those who reside in urban areas 
with a population of at least 50,000 are more likely to delay participation until after having a child.

State policies also influence the decision to delay participation. WIC participants residing in states where participation in SSI confers WIC eligibility are less likely to delay. Those living in states allowing for the tailoring to reduce sucrose content are more likely to delay. Counter to expectations, participants in states where participation in the free or reduced price school lunch program are more likely to delay, and a greater number of WIC offices per 1,000 poor individuals in the state is associated with a higher likelihood of delay. Understanding the relationship between state-level WIC policies and WIC participation can help inform decisions regarding policy design. However, these policies are likely to be correlated with other unobserved characteristics of the state, and therefore the coefficient estimates on these variables should be interpreted with caution. To test the sensitivity of our regression results to the inclusion of the state policy variables, we examine two other specifications of both the delayed entry and early exit equations. We estimate regression equations that exclude the WIC state policy variables and that include state fixed effects (results available from authors) and find that the main results are not sensitive to these two alternative specifications.

In addition to the two primary regression equations, we also estimate models for six key subgroups to determine the factors associated with delayed entry into WIC for each of the subgroups (results available from authors). The first five subgroups are disadvantaged households: (1) Hispanics, (2) high school dropouts over age 18, (3) teen mothers, (4) mothers in households with income below the poverty line, and (5) Medicaid participants. ${ }^{11}$ The final subgroup we examine are households in the Southern region. Not only does the South have the largest percent of eligible households in the prenatal period, the region also houses the largest

\footnotetext{
${ }^{11}$ Medicaid receipt is defined as participation in Medicaid in the postnatal period.
} 
percent of eligible non-participants during the prenatal period (Tiehen and Jacknowitz, 2007). Southern women also experience the highest rates of premature and low birthweight births (Martin et al, 2005). The results from the subgroup analyses (results available from authors) are generally consistent with those from main regression analysis of delayed entry. Participants who delay entry into WIC are generally more advantaged and less likely to receive prenatal Medicaid than those who begin WIC participation in the prenatal period. One interesting difference is that the WIC state policies appear to play a larger role in participation decisions for households residing in the Southern region.

\subsection{Child Leavers}

As shown in table 2, households who exit the program after a child turns one year of age exhibit better economic health along a variety of outcomes including household income, maternal employment before and after birth, assets, and participation in other assistance programs. Interestingly, households who exit are less likely to have breastfed their child for six months or more.

Table 3 shows the results of the probit regression of child exit from the WIC program. The estimated marginal effects from a probit regression with our parsimonious specification are displayed in column (3) and from our full specification including income change between waves in column (4). Again, since the results between the two models are similar, we focus on the full model in column (4). The results controlling for other variables suggests that households that exit the WIC program after the child turns one year old are more advantaged along a variety of dimensions than those that remain in the program. Households in which the mother has a college degree are more likely to exit, and those in which the mother has not been employed since the birth of her child are less likely to exit. In addition, households that have income below the 
poverty line, experienced a decrease in household income between the two survey waves, have participated in other programs since the birth of the child, and had the mother's prenatal care paid for by Medicaid are less likely to exit. In contrast, households in which the mother has smoked at least 100 cigarettes are more likely to exit WIC early.

As noted previously, our analysis sample consists of households who were determined to be eligible in the prenatal period. Therefore, it is possible that more advantaged households leave the WIC program because of a loss of program eligibility which we do not capture. We find some evidence for this in table 2, which shows that approximately half of leavers (50.9 percent) experienced an increase in household income between the two waves of the survey. Therefore, we restrict the sample to households whose household income either remained constant or decreased between the two waves of the survey. Our regression analysis (results available from authors) indicates that among households whose income did not increase, there is less evidence that more advantaged households are more likely to exit WIC. This suggests that the increased likelihood of program exit among more advantaged households in our primary analysis is partially driven by their loss in eligibility.

Further, households in which the mother never breastfed her infant or breastfed her infant for less than six months are more likely to exit than households in which the mother breastfed her infant for six months or more. ${ }^{12}$ This suggests that the transition from receipt of the infant food package, which contains infant formula, to receipt of the child food package plays a role in the decision to exit WIC. We further explore this explanation for children's exits by analyzing the difference in the retail value of the WIC food package for infants and the package for children. This detailed information, from the WIC Participants and Program Characteristics

\footnotetext{
${ }^{12}$ We estimate regression equations that are not weighted (results available from authors) and find that with the exception of the breastfeeding findings, our main results are largely similar to those presented.
} 
2000, is available for only 26 states and is therefore not included in the primary analysis. We find no evidence in our regression analysis (results available from the authors) that state-level differences in the retail value of the food packages influence the likelihood of exiting WIC. However, it may be that WIC participants have a similar perception of the change in the WIC benefit package when a child reaches age one, regardless of the differences in the retail value of the food packages.

We also examine early exits from WIC for the same six subgroups discussed in the previous section (results available from authors). While the results from the subgroup analysis are generally similar to the main results, there are some interesting differences. An increase in household income between the two surveys is associated with a greater likelihood of early exit from WIC in three of the subgroups, which is not evident in the full sample.

In addition to estimating the models identifying factors associated with postnatal/infant households that exit WIC during the child period we have information from a subset of mothers on why they stopped receiving WIC benefits for their child, including information on program ineligibility. ${ }^{13}$ Mothers were asked the following question, "Why are you no longer using WIC vouchers to buy food or formula for $\{$ CHILD $\}$ or $\{$ TWIN\}\}? Possible responses include "not eligible anymore," “eligible but denied benefit due to lack of program funds,” "no longer need food benefit," "program is too much effort (benefits are not worth the time and effort to get them)," "lack of transportation and/or scheduling problems," and "temporary administration issues prevent child from participating (plan to reapply to program).” Mothers are allowed to choose only one response. For those who exited, we present the self-reported explanations for exiting the WIC program. We then try to gain insight into the explanation for exits by comparing

\footnotetext{
${ }^{13}$ Not all mothers were asked about the reasons for their children exiting the WIC program early. Children who exited during the first wave of data were not asked about the reason for their exit. Households where only the mother participated in the postnatal period and then exited, did not get asked the survey question.
} 
selected characteristics of leavers who cited each explanation to the characteristics of nonleavers.

Table 4 shows that approximately 33 percent of exiting households report they no longer participate because they believe they are no longer eligible. This corroborates our sensitivity analysis above that suggested that loss of eligibility plays a role in child exits from WIC. Over one-fourth (27.2 percent) of mothers report that their children exit the program because they no longer need the food benefits. For households that report no longer being eligible or no longer needing food benefits, the program appears to be operating as intended. However, other explanations cited by mothers, including that the program is too much effort or that they have scheduling and transportation problems, suggest that the costs of participation may be a barrier to some children's continued participation in WIC. Interestingly, very few households (less than one percent) report that they are eligible for the program, but were denied benefits due to the lack of program funds. This is important evidence that, although WIC is not an entitlement program, the prevalence of waiting lists is quite low.

To gain further insight into these explanations for exits from WIC, we compare the characteristics of the exiting households who cite each of the four most frequent explanations for exit with those of non-leaver households in table $5 .{ }^{14}$ Leavers who state that they are no longer eligible and those who state that they no longer need the food benefits are generally more advantaged than non-leavers. Those who state they are no longer eligible are more likely to have had an increase in income, less likely to have had a decrease in income, are more likely to own a car or truck, and were less likely to participate in other assistance programs after the birth of their child. This suggests that these households are indeed ineligible or that the improvement in their

\footnotetext{
${ }^{14}$ For these comparisons, we report differences that are statistically significant at the 10 percent level because of small sample sizes for some of the subgroups of leavers.
} 
economic circumstances leads them to think they are ineligible. However, we can not disentangle the two explanations. Surprisingly, approximately 20 percent of households that cite they are no longer eligible experienced a decrease in income between waves. Further investigation into this group reveals nothing systematically different about them. Given the decrease in income, it is unlikely that they are indeed ineligible. It is possible that they are not clear about eligibility rules or that the decrease in income occurred after their assessment of eligibility. In addition, mothers in exiting households who state they no longer need food benefits are more likely to work after the birth of their child.

Children in leaver households who state they no longer need food benefits are more likely to have never been breastfed. This result corroborates the evidence from the multivariate regressions that infant feeding practices play a role in the decision to exit the program and suggests that some non-breastfeeding mothers who stop receiving infant formula when their child turns one do not perceive a need for the lower-value WIC benefits available in the child package.

The other two groups of leavers in table 5 indicate having problems related to WIC participation. Leavers who state the program is too much effort and the benefits are not worth the time are more likely to live in the South than non-leavers. This suggests that there may be program characteristics that make it more difficult for households to remain on the WIC program when a child reaches age one in the South than in other regions. Interestingly, exiting households that state they are no longer eligible are also more likely to live in the South than non-exiting households, which may also be a result of program characteristics. We compare the WIC policies of Southern states to those of states in other regions and find no evidence that Southern states systematically make it more difficult to participate in WIC. In fact, the average monthly WIC 
benefits provided by Southern states are higher than those provided by states in other regions. However, there may be something systematically different about the WIC program in the South that is not captured by the state policies included in our analysis.

Leavers who state program benefits are not worth the time are more likely to work after having their child, which would be expected to increase the time costs of participation and decrease the relative value of the benefits. These leavers also have about half as many WIC-only stores per 1,000 poor in their state of residence as non-leavers, which suggests that these stores reduce the transactions costs of participation. However, this group of leavers is also less likely to have their food voucher issued monthly, which is counter-intuitive. Discussions with WIC program staff indicate that agencies issuing vouchers more frequently may be providing more services and benefits, which could explain this result. Finally, households that cite transportation or scheduling problems as the explanation for their exit are less likely to live in a rural area, which is also an unexpected finding. It may reflect recent efforts to make WIC services more accessible in rural areas, or difficulty in scheduling or traveling to appointments in WIC agencies in large urban areas.

\section{Conclusion and Discussion}

As the benefits of WIC participation for pregnant women and children are welldocumented and these groups are less likely to participate in WIC than other categoricallyeligible groups, it is important to understand the reasons for their non-participation. If these nonparticipants are not eligible or do not need benefits then the program is functioning as intended. In contrast, if these groups demonstrate need but are not accessing benefits as a result of administrative costs or accessibility problems, then the program could be re-designed. This paper 
uses the first two waves of the ECLS-B data set to advance our understanding of factors explaining why eligible participant households are less likely to participate in the prenatal period and after a child turns one year of age than in the year after birth. Specifically, we examine factors associated with participants’ decisions to 1) delay their entry into the WIC program until the postnatal period and 2) exit WIC after the child turns one year of age. We use nationallyrepresentative data that provides information on WIC participation after recent changes in policy and contains rich information on factors associated with WIC participation. We employ a research design that allows us to reduce the role of stigma as a possible explanation for periods of non-participation and eliminate lack of program awareness as an explanation for households exiting after the child turns one year of age. This allows us to focus on other factors that may influence non-participation.

To answer the above research questions we first documents transitions into and out of the WIC program among eligible households. We find that 17.8 percent of postnatal/infant period participants did not participate during the prenatal period and that 22.6 percent of postnatal/infant period participants exit after their child turns one year of age, underscoring that these groups are not insignificant in size and warrant further study.

The results of our regression analysis indicate that more advantaged households are more likely to delay WIC participation until the postnatal period and more likely to exit after a child turns one year of age. The finding that more advantaged households are more likely to exit the program early is consistent with the results found by Burstein et al. (2000) and Gundersen (2005). We also find that prenatal Medicaid coverage is strongly correlated with earlier receipt of WIC. This suggests that each program may serve as a gateway for the other especially since those that receive Medicaid are adjunctively eligible for WIC. We also find that households who 
experience negative health outcomes around delivery are more likely to delay entry, which in part, implies that hospital outreach to increase WIC participation among eligible non-participants is effective. Results suggest that WIC's provision of infant formula and participants' breastfeeding decisions play a role in the early exit from the program. Women who breastfeed for a longer time are less likely to exit WIC. This is an interesting finding as most of the literature and outreach efforts have focused on the negative influence of WIC on breastfeeding (e.g., Chatterji et al., 2002; Jacknowitz, Novillo, and Tiehen, 2007). Other explanations that play a role in the early exit from the WIC program include loss of eligibility, reduced need, and difficulties accessing benefits.

Both the regression results indicating that more advantaged households are more likely to delay entry into the program and to exit early and results from maternal self-reports on explanations for exiting suggest that loss of eligibility plays a large role in non-participation. Results also suggest that non-participants have a reduced need for benefits. Such findings indicate that the program is operating effectively for many households. However, we find evidence that late entrants and leavers still exhibit need, suggesting that outreach or program reform is necessary to increase the duration of these participants' exposure to WIC services. For example, we find that women who exhibit worse health outcomes and health behaviors related to birth are more likely to delay entrance into WIC until the postnatal/infant period. These delayed entrants should ideally be enrolled early in the pregnancy in order to realize the potential benefits of WIC participation. In addition, mothers in participant households who do not breastfeed or breastfeed for less than 6 months are more likely to exit, and therefore warrant special attention by WIC agencies. 
Further, program re-design should be considered to address issues related to accessibility. For example, WIC offices could be open later or on weekends, and could be located near other social service offices or public transportation hubs to allow working mothers more opportunities to complete the required administrative documentation. Given that late entrants and leavers show a willingness to participate, outreach and program re-design efforts among this group should be effective.

While this study includes a comprehensive list of factors that may influence delayed entry into or early exit from the WIC program, there are additional factors that warrant future research as they may further program re-design. For example, future research could provide a more comprehensive examination of how changing eligibility status and the differences in the value of the WIC packages across participant categories influence changes in participation. 


\section{Appendix A: State-level WIC Policies and Practices}

\section{WIC Eligibility Variables}

States may offer automatic WIC income eligibility to individuals who participate in SSI or the Free or Reduced Price National School Lunch Program, or other means-tested transfer programs. Prior to 2000, some states required that applicants provide documentation of income (such as pay stubs, W-2 forms, and letters from employers), while other states allowed applicants to self-declare their income. Federal guidelines, effective in 2000, now require that all applicants provide income documentation, unless they are adjunctively eligible for WIC through participation in other means-tested transfer programs. The variables related to WIC eligibility are:

SSI confers WIC eligibility indicates whether participation in the Supplemental Security Income program confers automatic WIC income eligibility.

School lunch confers WIC eligibility indicates whether household participation in the free or reduced price lunch program confers automatic WIC income eligibility.

\section{WIC Food Package and Voucher Distribution Variables}

Federal guidelines limit the maximum amount of food states can distribute in each food package. Within this limit, state and local agencies may allow for food packages to be tailored to better meet the nutritional needs or preferences of individual WIC participants. For example, some states may allow WIC staff to tailor the types of milk, such as reduced-fat or soy, or to specify cereal with reduced sucrose content. States also have discretion over the frequency with which the vouchers (food instruments) are distributed to WIC participants, with distribution 
periods ranging from one month to three months. There are seven different WIC food packages, which vary by type of participant. The average retail cost of the food packages for all WIC participants varies by state (from $\$ 33.38$ to $\$ 61.84$ in 2000), depending on differences in food prices and tailoring allowances (USDA, 2002). The variables related to the WIC food package and voucher distribution are:

Food packages tailored for type of milk indicates whether a state allows for tailoring of the type of milk in food packages.

Food packages tailored to reduce sucrose indicates whether a state allows for tailoring of the type of cereal in food packages to reduce sucrose content.

WIC voucher issued monthly indicates that a pregnant participant must collect the WIC food voucher each month, rather than less frequently. Average retail value of WIC food packages is the real average cost of food packages for all WIC participants in 2000 dollars.

\section{WIC Offices and WIC-only Stores}

There were 2,196 local WIC offices in the United States in 2000. The share of WIC food sales in WIC-only stores, which serve only WIC customers, has increased dramatically in the past decade and in 2000, there were 523 WIC-only stores in 13 states (Neuberger and Greenstein, 2004). These stores carry only WIC products and may reduce the difficulties and stigma associated with redeeming WIC vouchers. The variables related to WIC offices and WIConly stores are:

WIC offices per 1,000 poor

WIC-only stores per 1,000 poor 


\section{WIC Nutritional Risk Variables}

To receive WIC, an applicant must be determined to be at nutritional risk. Although there is evidence that nearly all income-eligible individuals are at nutritional risk (Ver Ploeg and Betson, 2003), the documentation of nutritional risk can vary across states. Some states require dietary intake information from all participants as part of the nutritional risk assessment, while others require this information only from high-risk participants. There is also variation in the methods used to collect dietary intake information. The two most common collection methods routinely used by states are the twenty-four hour recall and the food frequency checklist. A recent study (Institute of Medicine, 2002), notes that 24-hour recall takes an average of 20 to 30 minutes to complete while a food frequency checklist takes an average of 10 to 15 minutes to complete. Most WIC applicants except infants take a blood test as part of the nutritional risk determination process. Prior to 1999, states selected criteria for establishing nutritional risk under broad federal guidelines. Low hematocrit or hemoglobin values indicate anemia or other nutritional abnormalities. The hematocrit and hemoglobin cutoff values reflect the stringency of the state's nutritional risk requirement prior to 1999, when federal guidelines required the standardization of nutritional risk criteria. The variables related to nutritional risk are:

All nutritional risk criteria documented indicates that the WIC agencies in the state document all of the nutritional risks faced by a participant, rather than documenting just the primary nutritional risks.

Dietary intake information required of all participants indicates whether states require that dietary intake information be collected from all participants, rather than just high-risk participants, to determine WIC nutritional risk eligibility. 
Twenty-four hour recall used to obtain dietary intake information indicates that the state routinely uses the 24-hour recall method to collect dietary intake information. 


\begin{tabular}{|c|c|c|c|c|c|c|}
\hline \multicolumn{5}{|c|}{ Participation pattern of group } & \multirow{2}{*}{$\begin{array}{c}\text { Value of } \\
\text { dependent } \\
\text { variable in } \\
\text { delayed entrance } \\
\text { model }\end{array}$} & \multirow{2}{*}{$\begin{array}{c}\text { Value of } \\
\text { dependent } \\
\text { variable in } \\
\text { early exit } \\
\text { model } \\
\end{array}$} \\
\hline $\begin{array}{l}\text { Group } \\
\text { number }\end{array}$ & $\begin{array}{c}\text { Participate } \\
\text { in prenatal } \\
\text { period? }\end{array}$ & $\begin{array}{c}\text { Participate in } \\
\text { postnatal/infant } \\
\text { period? }\end{array}$ & $\begin{array}{l}\text { Participate } \\
\text { in child } \\
\text { period? }\end{array}$ & $\begin{array}{c}\text { Included } \\
\text { in analysis } \\
\text { sample? }\end{array}$ & & \\
\hline 1 & $\mathrm{Y}$ & $\mathrm{Y}$ & $\mathrm{Y}$ & $\mathrm{Y}$ & 0 & 0 \\
\hline 2 & $\mathrm{Y}$ & $\mathrm{Y}$ & $\mathrm{N}$ & $\mathrm{Y}$ & 0 & 1 \\
\hline 3 & $\mathrm{Y}$ & $\mathrm{N}$ & $\mathrm{Y}$ & $\mathrm{Y}$ & - & - \\
\hline 4 & $\mathrm{Y}$ & $\mathrm{N}$ & $\mathrm{N}$ & $\mathrm{Y}$ & - & - \\
\hline 5 & $\mathrm{~N}$ & $\mathrm{Y}$ & $\mathrm{Y}$ & $\mathrm{Y}$ & 1 & 0 \\
\hline 6 & $\mathrm{~N}$ & $\mathrm{Y}$ & $\mathrm{N}$ & $\mathrm{Y}$ & 1 & 1 \\
\hline 7 & $\mathrm{~N}$ & $\mathrm{~N}$ & $\mathrm{Y}$ & $\mathrm{Y}$ & - & - \\
\hline 8 & $\mathrm{~N}$ & $\mathrm{~N}$ & $\mathrm{~N}$ & $\mathrm{~N}$ & - & - \\
\hline
\end{tabular}




\section{References}

Bitler, Marianne P., and Janet Currie. 2005. "Does WIC Work? The Effects of WIC on Pregnancy and Birth Outcomes." Journal of Policy Analysis and Management 24 (1): 7391.

Bitler, Marianne P., Janet Currie, and John Karl Scholz. 2003. "WIC Eligibility and Participation." Journal of Human Resources 38 (S): 1139-1179.

Bitler, Marriane P., Craig Gundersen, and Grace S. Marquis. 2005. "Are WIC Nonrecipients at Less Nutritional Risk Than Recipients? An Application of the Food Security Measure." Review of Agricultural Economics 27 (3): 433-438.

Brien, Michael J., and Christopher Swann. 2001. "Prenatal WIC Participation and Infant Health: Selection and Maternal Fixed Effects." Working paper.

Burstein, Nancy, Mary Kay Fox, Jordan Hiller, Robert Kornfeld, Ken Lam, Cristofer Price, and David T. Rodda. 2000. WIC General Analysis Project: Profile of WIC Children. Alexandria, VA: US Department of Agriculture, Food and Nutrition Service.

Chatterji, Pinka, Karen Bonuck, Simi Dhawan, and Nandini Deb. 2002. "WIC Participation and the Initiation and Duration of Breastfeeding." University of Wisconsin Institute for Research on Poverty Discussion Paper \#1246-02.

Currie, Janet. 2003. "US Food and Nutrition Programs." In Means-Tested Transfer Programs in the United States, by Robert Moffitt (ed.), 199-290. Chicago, IL: University of Chicago Press for NBER.

Currie, Janet. 2006. "The Take-up of Social Benefits." In Public Policy and the Distribution of, by Alan Auerbach, David Card, and John Quigley (eds.), 80-148. New York, NY: Russell Sage Press. 
Fox, Mary Kay, William Hamilton, and Bing-Hwan Lin. 2004. Effects of Food Assistance and Nutrition Programs on Nutrition and Health, Volume 3, Literature Review. Alexandria, VA: US Department of Agriculture, Food and Nutrition Service.

Gundersen, Craig. 2005. "A Dynamic Analysis of the Well-being of WIC Recipients and Eligible Non-recipients." Children and Youth Services Review 27 (1): 99-114.

Institute of Medicine. 2002. Dietary Risk Assessment in the WIC Program. Washington, DC: The National Academies Press.

Institute of Medicine. 2005. WIC Food Packages: Time for a Change. Washington, DC: The National Academies Press.

Jacknowitz, Alison, Daniel Novillo, and Laura Tiehen. 2007. "Special Supplemental Nutrition Program for Women, Infants, and Children and Infant Feeding Practices.” Pediatrics 119 (2): 281-289.

Joyce, Theodore, Diane Gibson, and Silvie Colman. 2005. "The Changing Association between Prenatal Participation in WIC and Birth Outcomes in New York City." Journal of Policy Analysis and Management 24 (4): 661-685.

Kowaleski-Jones, Lori, and Greg J. Duncan. 2000. "Effects of Participation in the WIC Food Assistance Program on Children's Health and Development: Evidence from NLSY Children.” University of Wisconsin Institute for Research on Poverty Discussion Paper \# 1207-00.

Ludwig, Jens, and Matthew Miller. 2005. "Interpreting the WIC Debate." Journal of Policy Analysis and Management 24 (3): 691-701. 
Martin, Joyce A, Brady E. Hamilton, Paul D. Sutton, Stephanie J. Ventura, Fay Menacker, and Martha L. Munson. 2005. “Births: Final Data for 2003.” National Vital Statistics Reports 54 (2). Hyattsville, MD: National Center for Health Statistics.

Neuberger, Zoe, and Robert Greenstein. 2004. WIC-Only Stores and Competitive Pricing in the WIC Program. Washington, DC: Center on Budget and Policy Priorities. Available at: http://www.cbpp.org/5-17-04wic.htm.

NGA Center for Best Practices. 2001. Maternal and Child Health (MCH) Update: States Have Expanded Eligibility and Increased Access to Health Care for Pregnant Women and Children. Washington, DC: NGA Health Policy Studies Division.

Nord, Christine, Brad Edwards, Carol Andreassen, James L. Green, and Kathleen Wallner-Allen. 2006. "Early Childhood Longitudinal Study, Birth Cohort (ECLS-B) User’s Manual for the ECLS-B Longitudinal 9-Month-2-Year Data File and Electronic Codebook (NCES 2006-046)." Washington, DC: US Department of Education, National Center for Education Statistics.

Swann, Christopher A. 2007. "The Timing of Prenatal WIC Participation." The B.E. Journals of Economic Analysis and Policy 7 (1-Topics): Article 5.

Tiehen, Laura, and Alison Jacknowitz. 2007. "Why Wait?: Examining Delayed WIC Participation Among Pregnant Women." Working paper.

US Department of Agriculture Food and Nutrition Service. 2002. WIC Participant and Program Characteristics 2000. Alexandria, VA: US Department of Agriculture, Food and Nutrition Service. 
US Department of Agriculture Food and Nutrition Service. 2003. WIC Participant and Program Characteristics 2002. Alexandria, VA: US Department of Agriculture, Food and Nutrition Service.

US Department of Agriculture Food and Nutrition Service. 2006. WIC Program Coverage: How Many Eligible Individuals Participated in the Special Supplemental Nutrition Program for Women, Infants, and Children (WIC): 1994 to 2003? Alexandria, VA: US Department of Agriculture, Food and Nutrition Service.

US Department of Agriculture Food and Nutrition Service. 2007. WIC Program Monthly Data. Alexandria, VA: US Department of Agriculture, Food and Nutrition Service, available at: http://www.fns.usda.gov/pd/wicmain.htm.

Ver Ploeg, Michelle, and David Betson. 2003. Estimating Eligibility and Participation for the WIC Program. Washington, DC: The National Academies Press. 


\section{Tables}

Table 1a. Percent of WIC participants who participate during the prenatal and postnatal/infant periods

\begin{tabular}{|c|c|c|}
\hline \multirow{2}{*}{$\begin{array}{c}\text { Prenatal WIC } \\
\text { participation }\end{array}$} & \multicolumn{2}{|c|}{ Postnatal/Infant WIC participation } \\
\cline { 2 - 3 } & No & Yes \\
\hline No & 2.7 & 16.6 \\
\hline Yes & 4.1 & 76.6 \\
\hline
\end{tabular}

Notes: Percentages are weighted. Sample size, rounded to the nearest 50 per NCES regulations, is 4,050 eligible households that participate in WIC in the prenatal, postnatal/infant, or child period. The no/no cell corresponds to groups 7 and 8 in Appendix B, the no/yes cell (delayed entrants) corresponds to groups 5 and 6 , the yes/no cell corresponds to groups 3 and 4, and the yes/yes cell corresponds to groups 1 and 2.

Table 1b. Percent of WIC participants who participate during the postnatal/infant period and as children

\begin{tabular}{|c|c|c|}
\hline \multirow{2}{*}{$\begin{array}{c}\text { Postnatal/Infant } \\
\text { WIC } \\
\text { participation }\end{array}$} & \multicolumn{2}{|c|}{ WIC participation as a child } \\
\cline { 2 - 3 } & No & Yes \\
\hline No & 1.8 & 5.0 \\
\hline Yes & 21.1 & 72.1 \\
\hline
\end{tabular}

Notes: Percentages are weighted. Sample size, rounded to the nearest 50 per NCES regulations, is 4,050 eligible households that participate in WIC in the prenatal, postnatal/infant, or child period. The no/no cell corresponds to groups 4 and 8 in Appendix B, the no/yes cell corresponds to groups 3 and 7 , the yes/no cell corresponds to groups 2 and 6 (leavers), and the yes/yes cell corresponds to groups 1 and 5 . 


\begin{tabular}{|c|c|c|c|c|c|}
\hline & \multirow[t]{2}{*}{$\frac{\underline{\text { Participates }}}{\underline{\text { in WIC in }}}$} & \multicolumn{2}{|c|}{$\frac{\text { Enters WIC in }}{\text { postnatal period }}$} & \multicolumn{2}{|c|}{$\frac{\text { Exits WIC as a }}{\underline{\text { child }}}$} \\
\hline & & Yes & No & Yes & No \\
\hline \multicolumn{6}{|l|}{ Mother's race } \\
\hline Non-Hispanic White & 0.388 & 0.400 & 0.388 & $0.439 *$ & 0.376 \\
\hline Non-Hispanic Black & 0.221 & 0.213 & 0.223 & 0.242 & 0.215 \\
\hline Hispanic & 0.342 & 0.326 & 0.342 & $0.266^{*}$ & 0.360 \\
\hline Asian & 0.017 & $0.034^{*}$ & 0.013 & 0.020 & 0.016 \\
\hline Other & 0.032 & 0.027 & 0.034 & 0.034 & 0.033 \\
\hline \multicolumn{6}{|l|}{ Mother's education } \\
\hline Less than high school & 0.474 & $0.428 *$ & 0.489 & $0.413^{*}$ & 0.497 \\
\hline High school graduate & 0.282 & 0.244 & 0.286 & 0.303 & 0.271 \\
\hline Some college or voc/tech degree & 0.213 & $0.272^{*}$ & 0.202 & 0.234 & 0.209 \\
\hline College degree & 0.031 & $0.056^{*}$ & 0.023 & $0.049 *$ & 0.023 \\
\hline \multicolumn{6}{|l|}{ Mother's age } \\
\hline Less than 20 years & 0.133 & 0.122 & 0.134 & 0.122 & 0.135 \\
\hline Age $20-24$ & 0.379 & $0.310^{*}$ & 0.395 & $0.425^{*}$ & 0.367 \\
\hline Age 25-29 & 0.256 & 0.275 & 0.254 & 0.267 & 0.255 \\
\hline Age 30-34 & 0.146 & 0.169 & 0.137 & 0.136 & 0.145 \\
\hline Age 35 or older & 0.086 & $0.125^{*}$ & 0.079 & $0.050 *$ & 0.098 \\
\hline \multicolumn{6}{|l|}{ Citizenship } \\
\hline Mother is a US citizen & 0.779 & 0.741 & 0.789 & $0.845^{*}$ & 0.761 \\
\hline \multicolumn{6}{|l|}{ Relationship status } \\
\hline Married & 0.422 & $0.493^{*}$ & 0.405 & 0.420 & 0.421 \\
\hline At least one other child under 5 in household & 0.390 & 0.379 & 0.399 & 0.410 & 0.391 \\
\hline At least one child age 5 to 17 in household & 0.456 & 0.480 & 0.451 & 0.424 & 0.465 \\
\hline Child is twin or higher-order birth & 0.017 & 0.021 & 0.016 & 0.015 & 0.018 \\
\hline Child is mother's first & 0.363 & 0.345 & 0.367 & 0.372 & 0.361 \\
\hline \multicolumn{6}{|l|}{ Region and urban area } \\
\hline Northeast & 0.144 & $0.221^{*}$ & 0.128 & 0.126 & 0.150 \\
\hline Midwest & 0.196 & 0.187 & 0.199 & 0.186 & 0.200 \\
\hline South & 0.411 & 0.378 & 0.416 & $0.460 *$ & 0.394 \\
\hline West & 0.249 & 0.215 & 0.258 & 0.227 & 0.257 \\
\hline Population of 50,000 and over & 0.682 & $0.752^{*}$ & 0.670 & 0.717 & 0.676 \\
\hline Population of 2,500 to 49,999 & 0.146 & 0.119 & 0.151 & 0.149 & 0.144 \\
\hline Population less than 2,500 & 0.172 & $0.130^{*}$ & 0.178 & $0.134 *$ & 0.180 \\
\hline \multicolumn{6}{|l|}{ Program participation } \\
\hline Participated in other programs since birth of child & 0.754 & $0.640 *$ & 0.783 & $0.712 *$ & 0.771 \\
\hline Mother received cash welfare most/all of childhood & 0.067 & 0.060 & 0.069 & 0.052 & 0.072 \\
\hline Mother received cash welfare some/half of childhood & 0.094 & $0.069 *$ & 0.099 & 0.093 & 0.093 \\
\hline Mother did not receive cash welfare as a child & 0.839 & $0.871^{*}$ & 0.833 & 0.855 & 0.835 \\
\hline
\end{tabular}




\begin{tabular}{|c|c|c|c|c|c|}
\hline & \multirow[t]{2}{*}{$\frac{\text { Participates }}{\underline{\text { in WIC in }}} \underline{\underline{\text { any period }}}$} & \multicolumn{2}{|c|}{$\frac{\text { Enters WIC in }}{\text { postnatal period }}$} & \multicolumn{2}{|c|}{$\frac{\text { Exits WIC as a }}{\text { child }}$} \\
\hline & & Yes & No & Yes & No \\
\hline \multicolumn{6}{|l|}{ Income/employment/assets } \\
\hline Household income (in thousands) & 21.474 & 22.478 & 21.139 & $23.413^{*}$ & 20.782 \\
\hline Household income increased & 0.463 & $0.519 *$ & 0.450 & $0.509 *$ & 0.448 \\
\hline Household income decreased & 0.315 & $0.265^{*}$ & 0.329 & 0.288 & 0.326 \\
\hline Household income stayed the same & 0.222 & 0.215 & 0.221 & 0.204 & 0.225 \\
\hline Below poverty line & 0.485 & 0.443 & 0.493 & $0.395 *$ & 0.511 \\
\hline Owns home & 0.215 & 0.224 & 0.211 & 0.231 & 0.208 \\
\hline Adult owns car or truck & 0.805 & 0.810 & 0.803 & $0.839 *$ & 0.794 \\
\hline Household invests & 0.113 & $0.150^{*}$ & 0.103 & $0.144^{*}$ & 0.102 \\
\hline Mother employed during year before birth & 0.644 & $0.690 *$ & 0.635 & $0.696 *$ & 0.630 \\
\hline Mother does not work anytime after birth & 0.331 & 0.334 & 0.324 & $0.264^{*}$ & 0.344 \\
\hline \multicolumn{6}{|l|}{ Prenatal care/Infant health } \\
\hline Prenatal care paid by private insurance & 0.229 & $0.370^{*}$ & 0.195 & $0.276^{*}$ & 0.211 \\
\hline Prenatal care paid by Medicaid & 0.659 & $0.495^{*}$ & 0.698 & $0.614^{*}$ & 0.675 \\
\hline $\begin{array}{l}\text { Prenatal care paid by neither Medicaid nor private } \\
\text { health insurance }\end{array}$ & 0.093 & $0.091^{*}$ & 0.095 & 0.083 & 0.098 \\
\hline No prenatal care received & 0.019 & 0.045 & 0.013 & 0.027 & 0.016 \\
\hline Gestational age at pregnancy recognition (weeks) & 6.149 & 6.010 & 6.239 & 6.031 & 6.247 \\
\hline $\begin{array}{l}\text { Mother smoked at least } 100 \text { cigarettes during her } \\
\text { lifetime }\end{array}$ & 0.373 & 0.350 & 0.384 & $0.430^{*}$ & 0.363 \\
\hline Child never breastfed & 0.409 & 0.406 & 0.412 & 0.428 & 0.406 \\
\hline Child breastfed under 6 months & 0.377 & 0.358 & 0.382 & 0.400 & 0.371 \\
\hline Child breastfed 6 months or more & 0.214 & 0.233 & 0.206 & $0.172 *$ & 0.222 \\
\hline Child low birthweight & 0.082 & 0.097 & 0.079 & 0.083 & 0.081 \\
\hline Premature birth & 0.128 & 0.122 & 0.128 & 0.122 & 0.128 \\
\hline Extra days in hospital due to medical problem & 2.023 & $2.488^{*}$ & 1.795 & 1.723 & 1.975 \\
\hline Received well-baby care from clinic & 0.397 & 0.393 & 0.399 & $0.338 *$ & 0.416 \\
\hline Received well-baby care from other & 0.024 & 0.018 & 0.025 & 0.021 & 0.025 \\
\hline Received well-baby care from doctor or HMO & 0.571 & 0.580 & 0.569 & $0.631 *$ & 0.553 \\
\hline Received no well-baby care & 0.009 & 0.009 & 0.007 & 0.011 & 0.006 \\
\hline \multicolumn{6}{|l|}{ State economic conditions } \\
\hline Unemployment rate & 4.013 & 3.975 & 4.025 & $3.952 *$ & 4.035 \\
\hline Poverty rate & 11.402 & $11.103^{*}$ & 11.468 & 11.339 & 11.422 \\
\hline \multicolumn{6}{|l|}{ State-level WIC policies and practices } \\
\hline SSI confers WIC eligibility & 0.083 & 0.085 & 0.084 & 0.079 & 0.085 \\
\hline School lunch confers WIC eligibility & 0.141 & $0.175^{*}$ & 0.129 & 0.143 & 0.136 \\
\hline Food packages tailored for type of milk & 0.863 & 0.869 & 0.864 & $0.890 *$ & 0.858 \\
\hline Food packages tailored to reduce sucrose & 0.094 & 0.103 & 0.092 & $0.156^{*}$ & 0.076 \\
\hline
\end{tabular}


Table 2. Characteristics of WIC participants by timing of WIC participation (continued)

\begin{tabular}{|c|c|c|c|c|c|}
\hline & \multirow[t]{2}{*}{ 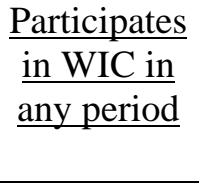 } & \multicolumn{2}{|c|}{$\frac{\text { Enters WIC in }}{\text { postnatal period }}$} & \multicolumn{2}{|c|}{$\frac{\text { Exits WIC as a }}{\underline{\text { child }}}$} \\
\hline & & Yes & No & Yes & No \\
\hline WIC voucher issued monthly & 0.228 & $0.183 *$ & 0.241 & $0.185^{*}$ & 0.245 \\
\hline Average retail value of WIC food packages (\$s) & 49.361 & 49.015 & 49.423 & 49.739* & 49.237 \\
\hline WIC offices per 1,000 poor & 0.071 & 0.075 & 0.070 & 0.070 & 0.072 \\
\hline WIC-only stores per 1,000 poor & 0.016 & 0.015 & 0.017 & $0.014^{*}$ & 0.017 \\
\hline All nutritional risk criteria documented & 0.725 & 0.764 & 0.718 & 0.717 & 0.728 \\
\hline Dietary intake information required of all participants & 0.859 & 0.862 & 0.864 & $0.823^{*}$ & 0.875 \\
\hline $\begin{array}{l}\text { Twenty-four hour recall used to obtain dietary intake } \\
\text { information }\end{array}$ & 0.786 & $0.743^{*}$ & 0.798 & 0.792 & 0.787 \\
\hline Observations & 4,050 & 700 & 3,050 & 800 & 2,950 \\
\hline
\end{tabular}

Notes: All means are weighted. Sample sizes are rounded to the nearest 50 per NCES regulations and therefore subgroup sample sizes do not equal to the total sample size.

* indicates that the value is significantly different from that of non-delayed entrants or non-leavers at the $5 \%$ level using a two-tailed test. 
Table 3. Marginal effects from probit regressions: Delayed entry or early exit from WIC participation among WIC participants

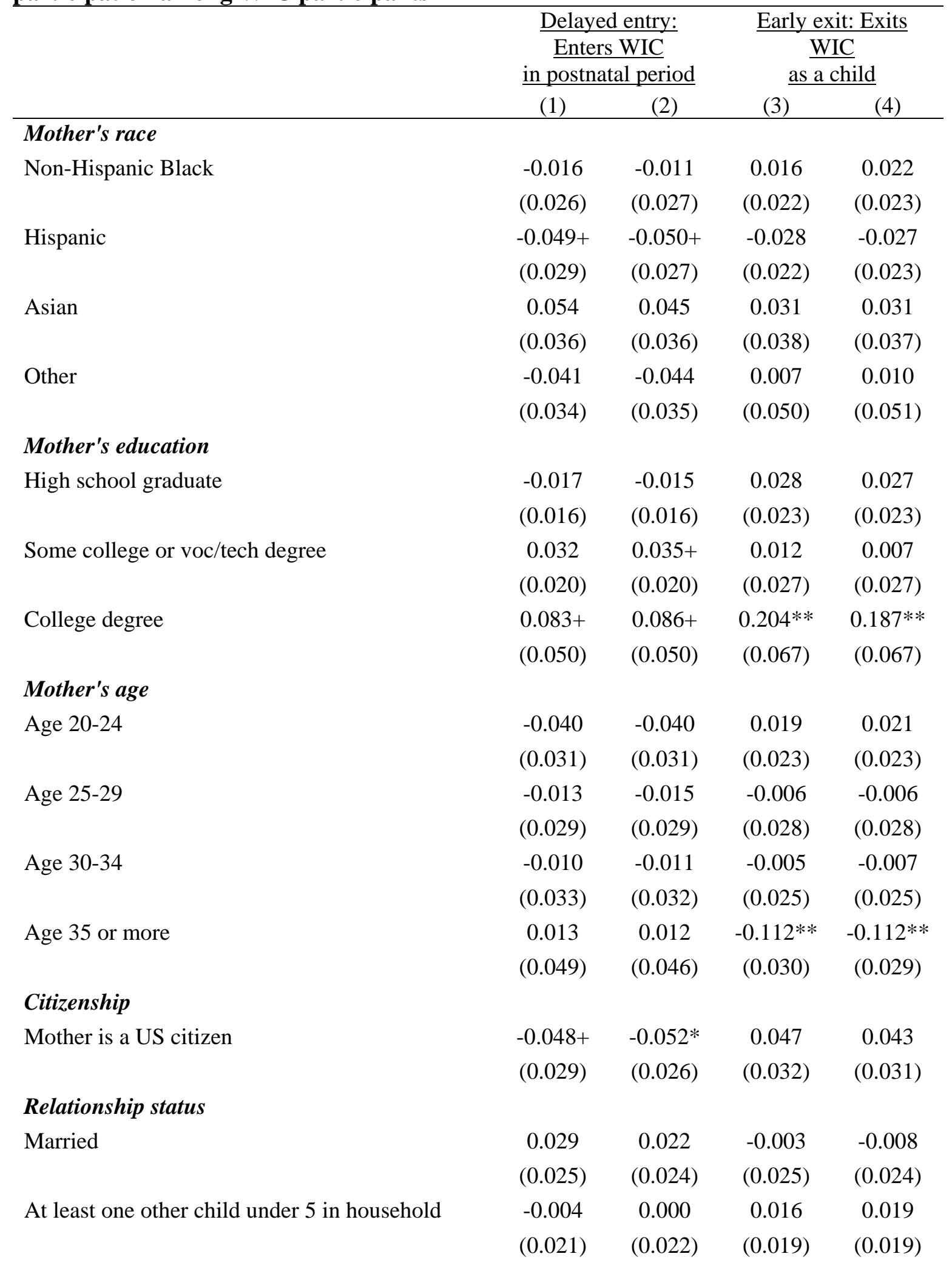


Table 3. Marginal effects from probit regressions: Delayed entry or early exit from WIC participation among WIC participants (continued)

\begin{tabular}{|c|c|c|c|c|}
\hline & \multicolumn{2}{|c|}{$\begin{array}{l}\frac{\text { Delayed entry: }}{\text { Enters WIC }} \\
\text { in postnatal period }\end{array}$} & \multicolumn{2}{|c|}{$\frac{\text { Early exit: Exits }}{\underline{\text { WIC }}}$} \\
\hline & (1) & (2) & (3) & (4) \\
\hline At least one child age 5 to 17 in household & $\begin{array}{l}-0.001 \\
(0.016)\end{array}$ & $\begin{array}{c}0.000 \\
(0.016)\end{array}$ & $\begin{array}{l}-0.014 \\
(0.022)\end{array}$ & $\begin{array}{l}-0.011 \\
(0.021)\end{array}$ \\
\hline Child is twin or higher-order birth & $\begin{array}{c}0.014 \\
(0.028)\end{array}$ & $\begin{array}{l}-0.003 \\
(0.023)\end{array}$ & $\begin{array}{c}-0.044+ \\
(0.024)\end{array}$ & $\begin{array}{l}-0.049 * \\
(0.022)\end{array}$ \\
\hline Child is mother's first & $\begin{array}{l}-0.003 \\
(0.026)\end{array}$ & $\begin{array}{l}-0.004 \\
(0.026)\end{array}$ & $\begin{array}{l}-0.011 \\
(0.025)\end{array}$ & $\begin{array}{l}-0.008 \\
(0.025)\end{array}$ \\
\hline \multicolumn{5}{|l|}{ Region and urban area } \\
\hline Northeast & $\begin{array}{l}0.143^{*} \\
(0.067)\end{array}$ & $\begin{array}{l}0.145^{*} \\
(0.067)\end{array}$ & $\begin{array}{l}-0.056 \\
(0.049)\end{array}$ & $\begin{array}{l}-0.057 \\
(0.048)\end{array}$ \\
\hline Midwest & $\begin{array}{c}0.035 \\
(0.035)\end{array}$ & $\begin{array}{c}0.034 \\
(0.036)\end{array}$ & $\begin{array}{l}-0.013 \\
(0.033)\end{array}$ & $\begin{array}{l}-0.012 \\
(0.031)\end{array}$ \\
\hline South & $\begin{array}{c}0.053 \\
(0.042)\end{array}$ & $\begin{array}{c}0.054 \\
(0.044)\end{array}$ & $\begin{array}{c}0.004 \\
(0.036)\end{array}$ & $\begin{array}{c}0.008 \\
(0.035)\end{array}$ \\
\hline Population of 2,500 to 49,999 & $\begin{array}{l}-0.043^{*} \\
(0.019)\end{array}$ & $\begin{array}{l}-0.040 * \\
(0.019)\end{array}$ & $\begin{array}{l}-0.013 \\
(0.034)\end{array}$ & $\begin{array}{l}-0.009 \\
(0.034)\end{array}$ \\
\hline Population less than 2,500 & $\begin{array}{l}-0.060 * \\
(0.024)\end{array}$ & $\begin{array}{l}-0.060 * \\
(0.024)\end{array}$ & $\begin{array}{c}-0.097 * * \\
(0.018)\end{array}$ & $\begin{array}{c}-0.096 * * \\
(0.018)\end{array}$ \\
\hline \multicolumn{5}{|l|}{ Program participation } \\
\hline Participated in other programs since birth of child & & $\begin{array}{l}-0.049 * \\
(0.023)\end{array}$ & $\begin{array}{c}-0.051+ \\
(0.028)\end{array}$ & $\begin{array}{c}-0.047+ \\
(0.027)\end{array}$ \\
\hline $\begin{array}{l}\text { Mother received cash welfare most/all of } \\
\text { childhood }\end{array}$ & $\begin{array}{l}-0.001 \\
(0.038)\end{array}$ & $\begin{array}{c}0.004 \\
(0.041)\end{array}$ & $\begin{array}{c}-0.038+ \\
(0.020)\end{array}$ & $\begin{array}{l}-0.031 \\
(0.020)\end{array}$ \\
\hline $\begin{array}{l}\text { Mother received cash welfare some/half of } \\
\text { childhood }\end{array}$ & $\begin{array}{l}-0.037 \\
(0.041)\end{array}$ & $\begin{array}{l}-0.032 \\
(0.041)\end{array}$ & $\begin{array}{c}0.004 \\
(0.027)\end{array}$ & $\begin{array}{c}0.010 \\
(0.027)\end{array}$ \\
\hline \multicolumn{5}{|l|}{ Income/employment/assets } \\
\hline Household income (in thousands) & $\begin{array}{c}0.001 \\
(0.001)\end{array}$ & $\begin{array}{l}0.001+ \\
(0.001)\end{array}$ & $\begin{array}{c}0.000 \\
(0.001)\end{array}$ & $\begin{array}{c}0.001 \\
(0.001)\end{array}$ \\
\hline Household income increased & & $\begin{array}{c}0.021 \\
(0.018)\end{array}$ & & $\begin{array}{c}0.040 \\
(0.026)\end{array}$ \\
\hline Household income decreased & & $\begin{array}{l}-0.022 \\
(0.014)\end{array}$ & & $\begin{array}{l}-0.035+ \\
(0.021)\end{array}$ \\
\hline Below poverty line & $\begin{array}{c}0.013 \\
(0.016)\end{array}$ & $\begin{array}{c}0.011 \\
(0.016)\end{array}$ & $\begin{array}{l}-0.037 \\
(0.024)\end{array}$ & $\begin{array}{l}-0.045+ \\
(0.023)\end{array}$ \\
\hline
\end{tabular}


Table 3. Marginal effects from probit regressions: Delayed entry or early exit from WIC participation among WIC participants (continued)

\begin{tabular}{|c|c|c|c|c|}
\hline & \multicolumn{2}{|c|}{$\begin{array}{c}\frac{\text { Delayed entry: }}{\text { Enters WIC }} \\
\text { in postnatal period } \\
\end{array}$} & \multicolumn{2}{|c|}{$\frac{\text { Early exit: Exits }}{\underline{\text { WIC }}}$} \\
\hline & (1) & $(2)$ & (3) & (4) \\
\hline \multirow[t]{2}{*}{ Owns home } & -0.017 & -0.021 & 0.015 & 0.010 \\
\hline & $(0.020)$ & $(0.020)$ & $(0.020)$ & $(0.019)$ \\
\hline \multirow[t]{2}{*}{ Adult owns car or truck } & -0.021 & -0.017 & 0.021 & 0.019 \\
\hline & $(0.030)$ & $(0.028)$ & $(0.020)$ & $(0.021)$ \\
\hline \multirow[t]{2}{*}{ Household invests } & 0.032 & 0.027 & 0.010 & 0.004 \\
\hline & $(0.023)$ & $(0.022)$ & $(0.022)$ & $(0.022)$ \\
\hline \multirow[t]{2}{*}{ Mother employed during year before birth } & 0.023 & $0.031+$ & 0.012 & 0.013 \\
\hline & $(0.017)$ & $(0.016)$ & $(0.021)$ & $(0.020)$ \\
\hline \multirow[t]{2}{*}{ Mother does not work anytime after birth } & & $0.022+$ & $-0.033^{*}$ & $-0.026+$ \\
\hline & & $(0.013)$ & $(0.015)$ & $(0.015)$ \\
\hline \multicolumn{5}{|l|}{ Prenatal care/Infant health } \\
\hline \multirow{2}{*}{$\begin{array}{l}\text { Prenatal care paid by Medicaid (can be in } \\
\text { combo) }\end{array}$} & $-0.145^{* *}$ & $-0.117 * *$ & -0.047 & -0.044 \\
\hline & $(0.025)$ & $(0.026)$ & $(0.033)$ & $(0.033)$ \\
\hline \multirow{2}{*}{$\begin{array}{l}\text { Prenatal care paid by neither Medicaid nor } \\
\text { private health insurance }\end{array}$} & $-0.077 * *$ & $-0.066 * *$ & -0.018 & -0.016 \\
\hline & $(0.017)$ & $(0.019)$ & $(0.049)$ & $(0.050)$ \\
\hline \multirow[t]{2}{*}{ No prenatal care received } & $0.118+$ & $0.146^{*}$ & 0.106 & 0.107 \\
\hline & $(0.079)$ & $(0.084)$ & $(0.092)$ & $(0.089)$ \\
\hline \multirow[t]{2}{*}{ Gestational age at pregnancy recognition } & 0.000 & 0.000 & -0.001 & -0.001 \\
\hline & $(0.001)$ & $(0.001)$ & $(0.001)$ & $(0.001)$ \\
\hline \multirow{2}{*}{$\begin{array}{l}\text { Mother smoked at least } 100 \text { cigarettes during her } \\
\text { lifetime }\end{array}$} & 0.005 & 0.004 & $0.049 *$ & $0.048 *$ \\
\hline & $(0.015)$ & $(0.014)$ & $(0.021)$ & $(0.022)$ \\
\hline \multirow[t]{2}{*}{ Child never breastfed } & & 0.014 & $0.035+$ & $0.039+$ \\
\hline & & $(0.018)$ & $(0.020)$ & $(0.021)$ \\
\hline \multirow[t]{2}{*}{ Child breastfed under 6 months } & & -0.007 & $0.036+$ & $0.038+$ \\
\hline & & $(0.020)$ & $(0.021)$ & $(0.021)$ \\
\hline \multirow[t]{2}{*}{ Child low birthweight } & & $0.045^{*}$ & 0.010 & 0.009 \\
\hline & & $(0.021)$ & $(0.017)$ & $(0.017)$ \\
\hline \multirow[t]{2}{*}{ Premature birth } & & -0.031 & 0.004 & 0.005 \\
\hline & & $(0.022)$ & $(0.028)$ & $(0.029)$ \\
\hline \multirow[t]{2}{*}{ Extra days in hospital due to medical problem } & & $0.001^{*}$ & -0.001 & -0.001 \\
\hline & & & $(0.001)$ & $(0.001)$ \\
\hline \multirow[t]{2}{*}{ Received well-baby care from clinic } & & 0.000 & -0.011 & -0.009 \\
\hline & & $(0.016)$ & $(0.014)$ & $(0.014)$ \\
\hline
\end{tabular}


Table 3. Marginal effects from probit regressions: Delayed entry or early exit from WIC participation among WIC participants (continued)

\begin{tabular}{|c|c|c|c|c|}
\hline & \multicolumn{2}{|c|}{$\begin{array}{l}\frac{\text { Delayed entry: }}{\text { Enters WIC }} \\
\text { in postnatal period }\end{array}$} & \multicolumn{2}{|c|}{$\frac{\text { Early exit: Exits }}{\underline{\text { WIC }}}$} \\
\hline & $(1)$ & $(2)$ & $(3)$ & (4) \\
\hline \multirow[t]{2}{*}{ Received well-baby care from other } & & -0.059 & -0.026 & -0.026 \\
\hline & & $(0.044)$ & $(0.034)$ & $(0.033)$ \\
\hline \multirow[t]{2}{*}{ Received no well-baby care } & & 0.111 & 0.113 & 0.129 \\
\hline & & $(0.131)$ & $(0.098)$ & $(0.102)$ \\
\hline \multicolumn{5}{|l|}{ State economic conditions } \\
\hline \multirow[t]{2}{*}{ Unemployment rate } & 0.002 & 0.002 & 0.003 & 0.006 \\
\hline & $(0.020)$ & $(0.020)$ & $(0.018)$ & $(0.018)$ \\
\hline \multirow[t]{2}{*}{ Poverty rate } & 0.001 & 0.001 & -0.006 & -0.007 \\
\hline & $(0.007)$ & $(0.007)$ & $(0.006)$ & $(0.006)$ \\
\hline \multicolumn{5}{|l|}{ State-level WIC policies and practices } \\
\hline \multirow[t]{2}{*}{ SSI confers WIC eligibility } & $-0.064^{*}$ & $-0.060^{*}$ & -0.038 & -0.039 \\
\hline & $(0.023)$ & $(0.024)$ & $(0.026)$ & $(0.027)$ \\
\hline \multirow[t]{2}{*}{ School lunch confers WIC eligibility } & $0.064+$ & $0.068+$ & -0.033 & -0.036 \\
\hline & $(0.036)$ & $(0.038)$ & $(0.029)$ & $(0.030)$ \\
\hline \multirow[t]{2}{*}{ Food packages tailored for type of milk } & -0.005 & -0.006 & 0.030 & 0.028 \\
\hline & $(0.035)$ & $(0.036)$ & $(0.025)$ & $(0.025)$ \\
\hline \multirow[t]{2}{*}{ Food packages tailored to reduce sucrose } & $0.057^{*}$ & $0.057 *$ & $0.116 * *$ & $0.118^{* *}$ \\
\hline & $(0.027)$ & $(0.027)$ & $(0.027)$ & $(0.027)$ \\
\hline \multirow[t]{2}{*}{ WIC voucher issued monthly } & -0.023 & -0.020 & -0.028 & -0.030 \\
\hline & $(0.037)$ & $(0.036)$ & $(0.028)$ & $(0.027)$ \\
\hline \multirow[t]{2}{*}{ Average retail value of WIC food packages (\$s) } & $-0.005+$ & $-0.005+$ & 0.004 & 0.004 \\
\hline & $(0.003)$ & $(0.003)$ & $(0.003)$ & $(0.003)$ \\
\hline \multirow[t]{2}{*}{ WIC offices per 1,000 poor } & $0.308^{*}$ & $0.302+$ & -0.051 & -0.067 \\
\hline & $(0.158)$ & $(0.162)$ & $(0.133)$ & $(0.131)$ \\
\hline \multirow[t]{2}{*}{ WIC-only stores per 1,000 poor } & 0.289 & 0.243 & -0.378 & -0.370 \\
\hline & $(0.637)$ & $(0.627)$ & $(0.654)$ & $(0.650)$ \\
\hline \multirow[t]{2}{*}{ All nutritional risk criteria documented } & 0.016 & 0.017 & 0.021 & 0.023 \\
\hline & $(0.037)$ & $(0.037)$ & $(0.022)$ & $(0.022)$ \\
\hline \multirow{2}{*}{$\begin{array}{l}\text { Dietary intake information required of all } \\
\text { participants }\end{array}$} & -0.017 & -0.013 & -0.012 & -0.012 \\
\hline & $(0.055)$ & $(0.055)$ & $(0.053)$ & $(0.053)$ \\
\hline \multirow{2}{*}{$\begin{array}{l}\text { Twenty-four hour recall used to obtain dietary } \\
\text { intake information }\end{array}$} & -0.038 & -0.033 & 0.059 & 0.062 \\
\hline & $(0.078)$ & $(0.078)$ & $(0.055)$ & $(0.056)$ \\
\hline
\end{tabular}


Table 3. Marginal effects from probit regressions: Delayed entry or early exit from WIC participation among WIC participants (continued)

\begin{tabular}{|c|c|c|c|c|}
\hline & \multicolumn{2}{|c|}{$\begin{array}{l}\frac{\text { Delayed entry: }}{\text { Enters WIC }} \\
\text { in postnatal period }\end{array}$} & \multicolumn{2}{|c|}{$\frac{\text { Early exit: Exits }}{\underline{\text { WIC }}} \underset{\text { as a child }}{ }$} \\
\hline & (1) & $(2)$ & (3) & (4) \\
\hline \multirow[t]{2}{*}{ Required X 24-hour recall } & 0.026 & 0.022 & -0.087 & -0.091 \\
\hline & $(0.071)$ & $(0.072)$ & $(0.073)$ & $(0.074)$ \\
\hline Observations & 3,750 & 3,750 & 3,750 & 3,750 \\
\hline
\end{tabular}

Notes: Estimates are weighted. Marginal effects are calculated at the means of the independent variables. Standard errors are in parentheses and adjusted to account for heteroskedasticity and multiple observations from the same state. Missing value indicator variables are included for the following variables: first birth, maternal receipt of welfare as a child, and premature status. Excluded groups are: Non-Hispanic White, less than high school, less than 20 years, West, population of 50,000 and over, mother did not receive cash welfare as a child, household income stayed the same, prenatal care paid by private health insurance, child breastfed 6 months or more, and received well-baby care from doctor or HMO. Sample sizes are rounded to the nearest 50 per NCES regulations.

+ significant at $10 \%, *$ significant at $5 \%$, ** significant at $1 \%$ 
Table 4. Explanations for early exits from the WIC Program after the child turns one year of age

\begin{tabular}{lc}
\hline Explanation & $\begin{array}{c}\text { Percent } \\
\text { reporting }\end{array}$ \\
\hline Not eligible anymore & 33.3 \\
No longer need food benefits & 27.2 \\
Program is too much effort-benefits are not worth the time & 25.7 \\
Lack of transportation and/or scheduling problems & 9.5 \\
Other & 2.6 \\
Temporary administrative issues prevent participation, but plan to participate & 0.1 \\
again & 0.5 \\
\hline Eligible, but denied benefits due to lack of program funds & 600 \\
\hline
\end{tabular}

Notes: Percentages are weighted. Sample size is rounded to the nearest 50 per NCES regulations. 


\begin{tabular}{|c|c|c|c|c|c|}
\hline Household characteristic & $\begin{array}{l}\text { Non- } \\
\text { leavers }\end{array}$ & $\begin{array}{c}\text { No } \\
\text { longer } \\
\text { eligible }\end{array}$ & $\begin{array}{c}\text { No longer } \\
\text { need food } \\
\text { benefits }\end{array}$ & $\begin{array}{l}\text { vers by reason } \\
\text { Program is too } \\
\text { much effort- } \\
\text { benefits are not } \\
\text { worth the time }\end{array}$ & $\begin{array}{c}\text { Transportation } \\
\text { and scheduling } \\
\text { problems }\end{array}$ \\
\hline $\begin{array}{l}\text { At least one other child under } 5 \text { in } \\
\text { household }\end{array}$ & 0.391 & 0.374 & 0.409 & 0.350 & 0.458 \\
\hline South & 0.394 & $0.492 *$ & 0.433 & $0.564 * *$ & 0.465 \\
\hline Population of 50,000 and over & 0.676 & 0.672 & 0.743 & 0.680 & 0.767 \\
\hline Population of 2,500 to 49,999 & 0.144 & 0.168 & 0.171 & 0.125 & 0.157 \\
\hline Population less than 2,500 & 0.180 & 0.160 & $0.086 * *$ & 0.195 & $0.077 * *$ \\
\hline $\begin{array}{l}\text { Participated in other programs since } \\
\text { birth of child }\end{array}$ & 0.771 & $0.593 * *$ & 0.706 & 0.778 & 0.839 \\
\hline Household income increased & 0.448 & $0.610 * *$ & 0.496 & 0.500 & 0.411 \\
\hline Household income decreased & 0.326 & $0.198 * *$ & 0.257 & 0.327 & 0.367 \\
\hline Adult owns car or truck & 0.794 & $0.883 * *$ & 0.820 & 0.771 & 0.823 \\
\hline $\begin{array}{l}\text { Mother does not work anytime after } \\
\text { birth }\end{array}$ & 0.344 & 0.303 & $0.225^{* *}$ & $0.256+$ & 0.303 \\
\hline Child never breastfed & 0.406 & 0.383 & $0.503+$ & 0.479 & 0.405 \\
\hline Child breastfed under 6 months & 0.371 & 0.386 & 0.375 & 0.397 & 0.469 \\
\hline SSI confers WIC eligibility & 0.085 & 0.102 & 0.089 & $0.045^{*}$ & 0.046 \\
\hline School lunch confers WIC eligibility & 0.136 & 0.130 & 0.156 & 0.119 & 0.157 \\
\hline $\begin{array}{l}\text { Food packages tailored for type of } \\
\text { milk }\end{array}$ & 0.858 & $0.903+$ & 0.863 & 0.897 & 0.792 \\
\hline $\begin{array}{l}\text { Food packages tailored to reduce } \\
\text { sucrose }\end{array}$ & 0.076 & $0.153^{*}$ & $0.155^{*}$ & $0.208 * *$ & 0.162 \\
\hline WIC voucher issued monthly & 0.245 & $0.179 *$ & 0.229 & $0.060 * *$ & 0.197 \\
\hline $\begin{array}{l}\text { Average retail value of WIC food } \\
\text { packages (\$s) }\end{array}$ & 49.24 & 49.73 & 49.72 & $50.34 * *$ & 49.63 \\
\hline WIC offices per 1,000 poor & 0.072 & 0.071 & 0.070 & 0.072 & 0.066 \\
\hline WIC-only stores per 1,000 poor & 0.017 & 0.014 & 0.015 & $0.008 * *$ & 0.013 \\
\hline $\begin{array}{l}\text { All nutritional risk criteria } \\
\text { documented }\end{array}$ & 0.728 & 0.696 & 0.661 & 0.733 & 0.718 \\
\hline $\begin{array}{l}\text { Dietary intake information required } \\
\text { of all participants }\end{array}$ & 0.875 & $0.784^{*}$ & $0.802+$ & 0.866 & 0.904 \\
\hline $\begin{array}{l}\text { Twenty-four hour recall used to } \\
\text { obtain dietary intake information }\end{array}$ & 0.787 & 0.792 & 0.803 & 0.719 & 0.849 \\
\hline Observations & 2,950 & 200 & 150 & 150 & 50 \\
\hline
\end{tabular}

Notes: All means are weighted. Sample sizes are rounded to the nearest 50 per NCES regulations.

Superscripts **, *, or + indicate that the value is significantly different from that of non-leavers at the $1 \%, 5 \%$, or $10 \%$ level respectively, using a two-tailed test. 